\title{
Combination of valproate and paroxetine in mice exposed to picrotoxin
}

\author{
This article was published in the following Dove Press journal: \\ International Journal of Nanomedicine \\ 22 May 2012 \\ Number of times this article has been viewed
}

\author{
Sahar M Kamal \\ Department of Pharmacology, Faculty \\ of Medicine, University of Ain-Shams, \\ Cairo, Egypt
}

\begin{abstract}
The frequent coexistence of depression in epileptic patients raises the issue of simultaneous use of antidepressants along with antiepileptic drugs in the management of such cases. However, it is necessary to evaluate the safety of these antiepileptic/antidepressant drug combinations. The present study investigates the effect of the antidepressant paroxetine (a selective serotonin reuptake inhibitor) administered alone or in combination with the antiepileptic drug sodium valproate on chemoconvulsions induced by picrotoxin (PTX). Seizure score was recorded in vivo, and the levels of thiobarbituric acid-reactive substances and gamma aminobutyric acid (GABA) were measured in the nucleus accumbens of the tested groups of mice. The results show enhancement of seizure severity with significant reduction in GABA levels upon PTX treatment that were reversed by its combination with sodium valproate. On the other hand, paroxetine administered in combination with sodium valproate provided significant protection against PTX-induced convulsions as well as a significant increase in GABA levels in selected brain areas. These results favor their application in management of epilepsy-depression comorbidities.
\end{abstract}

Keywords: valproate, paroxetine, GABA, nucleus accumbens, albino mice

\section{Introduction}

Epilepsy is one of the most common neurological disorders characterized by recurring excessive neuronal discharge, exhibited by transient episodes of motor, sensory, or psychic dysfunction, with or without unconsciousness or convulsive movements. In addition, epilepsy may be associated with neurodegeneration, presumably due to abnormal lipid peroxidation. ${ }^{1,2}$ On the other hand, comorbid depression is common in patients with epilepsy. A review of available studies ${ }^{3}$ suggested a high prevalence of mood (affective) disorders, especially major depression $(8 \%-48 \%)$, followed by anxiety $(5 \%-32 \%)$, in patients with epilepsy. Although the mechanisms underlying the epilepsy-depression relationship have not been clearly identified, depression in epileptic cases is multifaceted with many interacting neurobiological and psychosocial determinants. These include clinical features of epilepsy (seizure frequency, type, foci, or lateralization of foci) and neurochemical or iatrogenic mechanisms., ${ }^{4,5}$

Serotonin and norepinephrine are the most studied neurotransmitters in mood disorders. A decrease in the functional activity of central serotonergic and catecholaminergic systems is probably associated in major depressive episodes. ${ }^{6}$ Applying an appropriate strategy with drugs targeting both neurotransmitter systems may improve the efficacy of the antidepressant treatment. Antidepressant drugs are either selective serotonin reuptake inhibitors (SSRIs), eg, paroxetine, or mixed serotonin/noradrenaline 
reuptake inhibitors (SNRIs), eg, venlafaxine and duloxetine. ${ }^{7,8}$ SSRIs, such as paroxetine and citalopram, are effective in treating depressed patients. ${ }^{9,10}$ However, other neurotransmitter systems may also be involved in the pathogenesis of depression as a gamma aminobutyric acid (GABA)ergic system that is considered to be implicated in the pathogenetic mechanisms of mood disorders. ${ }^{11}$

The high prevalence of depression in epileptic patients may necessitate the addition of an antidepressant agent in therapy. However, the use of antidepressant drugs in epileptics has been a matter of debate for clinicians because of reports that these drugs may have frank convulsant or proconvulsant effects that increase seizure incidence. ${ }^{12}$ This might happen due to modulation of pre- and/or postsynaptic receptor function and rate of release of neurotransmitters such as $\gamma$-amino butyric acid, noradrenaline, dopamine, or serotonin, ${ }^{13,14}$ so it is important to recognize and assess possible implications of antiepileptic/antidepressant drug combinations in the management of epileptic cases complicated by depression.

The rationale of the present study is to (1) evaluate the seizure score of the antiepileptic drug sodium valproate with the antidepressant paroxetine in the management of chemically induced seizures in chronically restrained mice, and (2) study the effect of these drug combinations on thiobarbituric acid-reactive substances (TBARS) as a marker of lipid peroxidation and GABA levels in nucleus accumbens in tested mice.

\section{Materials and methods Drugs and chemicals}

Picrotoxin (PTX; Sigma-Aldrich Co, St Louis, MO), paroxetine $\mathrm{HCl}$ (GlaxoSmithKline, Brentford, Middlesex, UK), sodium valproate (2-propyl pentanoic acid-Na salt; Sigma-Aldrich Co), GABA and L-norvaline standards (Sigma-Aldrich Co), ethanol (high-performance liquid chromatography [HPLC] grade; Merck and Co, Inc, Whitehouse Station, NJ), triethylamine (Merck and Co, Inc), phenylisothiocyanate (PITC; Sigma-Aldrich Co), hydrochloric acid (32\%, Merck and Co, Inc), acetonitrile (Merck and Co, Inc), glacial acetic acid (Sigma-Aldrich $\mathrm{Co}$ ), and sodium acetate anhydrous (Merck and Co, Inc).

\section{Animals}

Albino mice (20-25 g) were divided into four groups with 12 mice each. They were housed in cages with a natural light-dark cycle and fed on a standard pellet diet and water ad libitum.

\section{Picrotoxin-induced convulsions}

All mice were given a single subcutaneous dose $(3.5 \mathrm{mg} / \mathrm{kg}$ body weight) of PTX either in the absence of any treatment (control group) or following administration of a single dose of the test drug(s) (treated groups). Accordingly, the study comprised the following four groups:

1. Control group receiving neither antiepileptic nor antidepressant treatment.

2. Sodium valproate-treated group: received sodium valproate dissolved in water $(30 \mathrm{mg} / \mathrm{kg}$ body weight intraperitoneal) per Siddiqui, A et al ${ }^{15}$

3. Paroxetine-treated group: was administered paroxetine dissolved in saline ( $1 \mathrm{mg} / \mathrm{kg}$ body weight intraperitoneal). This dose was selected according to David, D et al. ${ }^{16}$

4. Sodium valproate/paroxetine-treated group: given sodium valproate and paroxetine treatment in doses of $30 \mathrm{mg} / \mathrm{kg}$ body weight intraperitoneal and $1 \mathrm{mg} / \mathrm{kg}$ body weight intraperitoneal, respectively.

In the treated groups, PTX was injected after a suitable latency corresponding to the time expected to reach a peak effect following administration of the respective test drug(s). The latency of both tested drugs was estimated to be 1 hour after their intraperitoneal administration, as determined by the pilot study.

Immediately after administration of PTX, the animal was observed for 30 minutes. The onset of convulsive behavior as well as the nature and severity of convulsions were carefully recorded using the scoring system 1-7 as follows: hyperlocomotion or piloerection (erection of the skin hair), 1; stunning (immobile) or catatonic posture (assuming a fixed posture and inability to move), 2; clonic body tremors (a series of involuntary muscular contractions due to sudden stretching of the muscle), 3; prolonged clonic tremors, 4; tonic forelimb convulsions followed by clonus, 5 ; repetitive tonic (prolonged muscular contraction) forelimb convulsions followed by clonus, 6; and tonic extension of both forelimbs and hindlimbs followed by clonus, 7; a mean cumulative score was calculated for each treatment group for comparisons and statistical analysis. At the end of the PTX study for each group, the animals were returned to their cages to continue with the chronic restraint stress study.

\section{Chronic restraint stress procedure}

Each mouse of the respective group was placed in a wire mesh restrainer 6 hours daily for 21 days. At the end of the restraint period, the mice were moved to their cages. 
Measurement of nucleus accumbens TBARS as a marker of lipid peroxidation

At the end of the 21 days of restraint stress, nucleus accumbens was excised out of the brain and rinsed with cold $0.14 \mathrm{M} \mathrm{NaCl}$, and part of it was homogenized in $25 \%$ ice cold $50 \mathrm{mM}$ Tris-HCl buffer, $\mathrm{pH}$ 7.4. ${ }^{17}$ One hundred and fifty microliters of the tissue supernatant of samples was diluted to $500 \mu \mathrm{L}$ with deionized water. A total of $250 \mu \mathrm{L}$ of $1.34 \%$ thiobarbituric acid was added to all the tubes, followed by the addition of an equal volume of $40 \%$ trichloroacetic acid. The mixture was shaken and incubated for 30 minutes in a boiling water bath. Tubes were allowed to cool to room temperature and the absorbance was read at $532 \mathrm{~nm}$ using zero concentration as blank. ${ }^{18}$

Determination of GABA in homogenates of nucleus accumbens isolated from tested mice

The GABA level in the tissue homogenates of the nucleus accumbens was determined. ${ }^{8,19-21}$ The HPLC method with precolumn PITC derivatization was used for the determination of GABA levels in the homogenate of the nucleus accumbens of the brains of mice of different groups. The measurement scale of the data was in nmol/mg tissue protein.

Parts of the homogenates of nucleus accumbens were centrifuged in a cooling $\left(4^{\circ} \mathrm{C}\right)$ centrifuge at $15,000 \mathrm{rpm}$ for 10 minutes. The supernatant was aspirated and transferred to an Eppendorff tube, while the pellet was kept at $-70^{\circ} \mathrm{C}$ until assayed for its total protein content. ${ }^{22}$ According to Gunawan et al, ${ }^{19}$ each sample was derivatized via drying $100 \mu \mathrm{L}$ of the aspirated supernatant in the centrivap, under vacuum. The residue was dissolved in $20 \mu \mathrm{L}$ of ethanol-water-triethylamine (2:2:1) and evaporated to dryness under vacuum. A $30 \mu \mathrm{L}$ mixture of ethanol-water-triethylamine-PITC $(7: 1: 1: 1)$ was added to the residue and allowed to react for 20 minutes at room temperature to form the PITC derivatives of the amino acids. Excess reagent was then evaporated under vacuum. The mobile phase of HPLC consisted of solvents A and B: solvent A: $0.1 \mathrm{M}$ sodium acetate buffer $(\mathrm{pH}=5.8)$, solvent B: acetonitrile: water $(60: 40, \mathrm{v}: \mathrm{v})$. A mixture of $80 \%$ solvent A and 20\% solvent B was adjusted for the "isocratic" HPLC separations. Flow rate was set at $0.6 \mathrm{~mL} /$ minutes. The injected sample was $20 \mu \mathrm{L}$. The peaks were detected at $254 \mathrm{~nm}$ wave length. Standard curves for GABA and norvaline were plotted using norvaline $2 \mathrm{nmol} / 20 \mu \mathrm{L}$ as an internal standard. The ratio of the peak area of each concentration of each standard to the peak area of the internal standard was determined and entered against the concentration of the standard, in a simple regression procedure.

\section{Protein determination}

The total protein content of nucleus accumbens homogenate was determined. ${ }^{22}$

\section{Data analysis}

The results were presented as medians with 25 and 75 percentiles for seizure score and mean \pm standard deviation for seizure onset. Additionally, the contents of TBARS as a marker of lipid peroxidation and GABA in nucleus accumbens of tested mice of all groups were expressed in $\mathrm{nmol} / \mathrm{mg}$ tissue protein as mean \pm standard deviation. Data were analyzed using one-way analysis of variance with Tukey $t$-test at a 95\% confidence level with significant differences between groups at $P<0.05$.

\section{Results}

\section{Effect of different drug treatment regimens on PTX-induced convulsions}

Single sodium valproate treatment significantly $(P<0.05)$ delayed the onset and reduced the severity of PTX-induced convulsions compared with the control group. On the other hand, treatment with paroxetine alone significantly $(P<0.05)$ delayed the onset and reduced the severity of convulsions compared with the control group. However, it was significantly $(P<0.05)$ less effective than single sodium valproate treatment with respect to prolonging onset latency or reducing severity of convulsions. Treatment with both drugs significantly $(P<0.05)$ delayed the onset and reduced the severity score of convulsions in comparison with all other groups (Table 1).

\section{Effect of tested drugs on TBARS in $\mathrm{nmol} / \mathrm{mg}$ tissue protein in nucleus accumbens of mice exposed to chronic restraint model}

Sodium valproate administration to group 2 significantly $(P<0.05)$ lowered TBARS level compared with the control group. Coadministration of paroxetine with sodium valproate significantly $(P<0.05)$ reduced TBARS level compared with the control, sodium valproate, or paroxetine groups (Figure 1).

\section{Effect of tested drugs on the GABA level in the nucleus accumbens of tested mice}

Sodium valproate administration to group 2 significantly $(P<0.05)$ increased GABA level compared with the control group. Coadministration of paroxetine with sodium 
Table I Effect of different drug treatment regimens on picrotoxin (PTX)-induced convulsions

\begin{tabular}{|c|c|c|c|c|c|c|}
\hline \multirow[t]{2}{*}{ Group } & \multirow[t]{2}{*}{ Treatment } & \multirow{2}{*}{$\begin{array}{l}\text { Dose } \\
(\mathrm{mg} / \mathrm{kg})\end{array}$} & \multirow{2}{*}{$\begin{array}{l}\text { Onset of convulsions } \\
\text { (seconds) }\end{array}$} & \multicolumn{3}{|c|}{ Severity (score range I-7) } \\
\hline & & & & $25 \%$ & Median & $75 \%$ \\
\hline $\mathrm{I}$ & PTX (sc) & 3.5 & $449.2 \pm 26.24$ & 5 & 5 & 5 \\
\hline 2 & Sodium valproate (ip) & 50 & $1408 \pm 79.95^{\mathrm{a}}$ & I & $I^{a}$ & 2 \\
\hline 3 & Paroxetine (ip) & 2.5 & $714.8 \pm 22.92^{\mathrm{a}}$ & 3 & 4 & 4 \\
\hline 4 & Sodium valproate + paroxetine (ip) & $50+8$ & $1724 \pm 52.65^{\mathrm{a}, \mathrm{b}}$ & 1 & $\mathrm{I}^{\mathrm{a}}$ & I \\
\hline
\end{tabular}

Notes: Modulation of onset and severity of PTX-induced convulsions in mice treated with either sodium valproate or paroxetine (groups 2 and 3 ), while in group 4 paroxetine was given in combination with sodium valproate. Treatment with sodium valproate significantly $(P<0.05)$ delayed onset of convulsions and reduced their severity score compared with the control group. On the other hand, single treatment with paroxetine significantly $(P<0.05)$ delayed onset of convulsions compared with the control group, and when combined with sodium valproate it further significantly $(P<0.05)$ reduced the convulsion severity score compared with the other groups. ${ }^{\text {a }} P<0.05$ compared with control group; ${ }^{\mathrm{b}} P<0.05$ compared with sodium valproate group.

Abbreviations: ip, intraperitoneal; sc, subcutaneous.

valproate significantly $(P<0.05)$ increased GABA level if compared with the control, sodium valproate, or paroxetine groups (Figure 2).

\section{Discussion}

The high incidence of psychiatric comorbidities, especially depression and anxiety, seen in epileptic patients may require treatment of both disorders at the same time with a combination of antiepileptic and psychotropic drugs. Therefore, the safety of these drug combinations should be evaluated in order to optimize the treatment of epilepsy. Interestingly, some antiepileptic drugs have a complex of proconvulsant

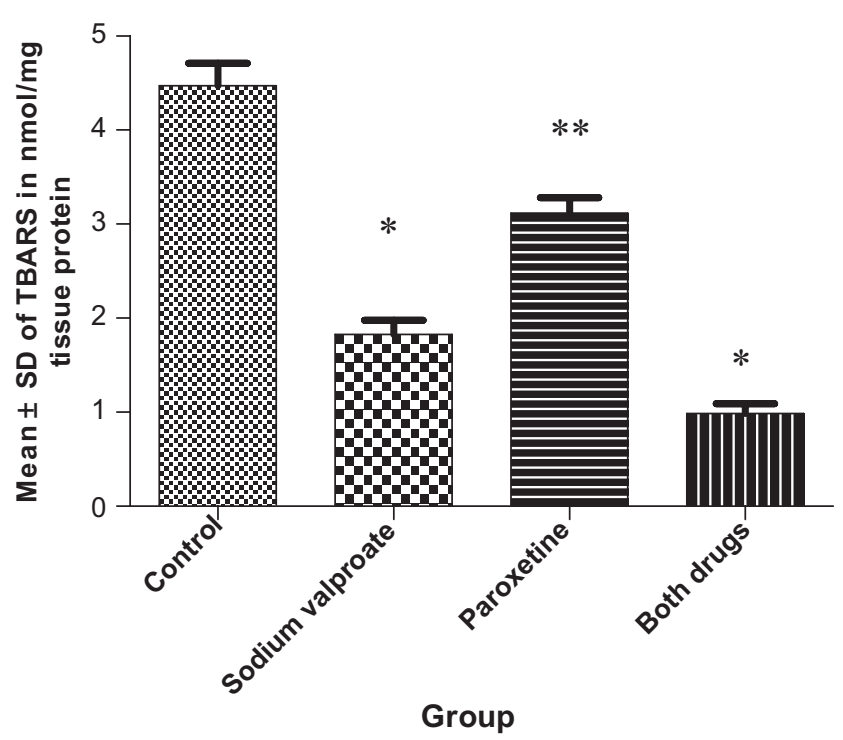

Figure I Effect of tested drugs on thiobarbituric acid-reactive substances (TBARS) in $\mathrm{nmol} / \mathrm{mg}$ tissue protein in nucleus accumbens of mice exposed to a chronic restraint model.

Notes: Changes in cortical TBARS levels upon treatment with either sodium valproate or paroxetine given alone or in combination with each other. Administration of sodium valproate resulted in a significant $(P<0.05)$ reduction in the TBARS content of nucleus accumbens compared with groups $I$ and 3 , while paroxetine in combination with sodium valproate (group 4) significantly reduced TBARS content when compared with either the valproate-only treated group or the paroxetinetreated group (groups 2 and 3 ). $* P<0.05$ significant decrease compared with groups I and 3; **P $<0.05$ significant increase compared with groups 2 and 4 . and anticonvulsant activities. ${ }^{23}$ On the other hand, although the risk of antidepressant-induced seizures, in general, is very low, most, if not all, antidepressant agents have a propensity to lower the seizure threshold, and most are associated with a clinical risk of seizures. The mechanism by which antidepressants cause seizures, however, is still not well established. Recently, it has been suggested that the proconvulsant effects of antidepressants may be attributed to their local anesthetic, antimuscarinic, or anti-histaminic properties..$^{20}$

Although many studies report that use of older antidepressants, eg, monoamine oxidase inhibitors and tricyclic antidepressants, is frequently associated with the risk of seizures, ${ }^{24,25}$ the newer antidepressants, eg, SSRIs and SNRIs, are claimed to exhibit a better tolerability profile for most patients.

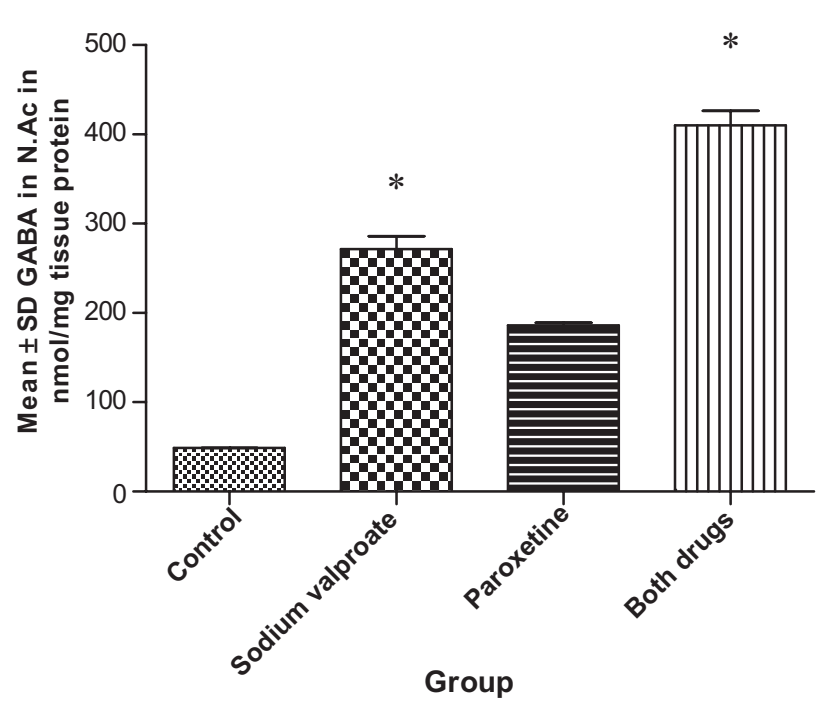

Figure 2 Effect of tested drugs on the gamma aminobutyric acid (GABA) level in the nucleus accumbens of tested mice.

Note: Sodium valproate significantly $(P<0.05)$ increased the GABA concentration in the nucleus accumbens of mice of group 2 compared with group I. GABA concentration of chronic mild stress mice was significantly increased $(P<0.05)$ by both sodium valproate and paroxetine compared with all tested groups. $* P<0.05$ significant increase compared with groups I and 3 . 
The safety of such agents should still be thoroughly assessed for clinical application in epileptic cases.

There is great debate about the use of SSRIs in the management of depression complicating epileptic cases. There are old reports about the increase in seizure frequency and intensity by SSRIs. ${ }^{26,27}$ Surprisingly, though the reports about proconvulsive actions of SSRIs are ever increasing, these agents are still widely used in epileptics to treat accompanying depression. ${ }^{28}$

Meanwhile, there is rising interest to study the possible mechanism of action of many antidepressants on GABA. This amino acid is the major inhibitory neurotransmitter in the brain that diminishes the activity of its target neurons. It also modulates the activity of several neurotransmitters, including dopamine, serotonin, and norepinephrine. It is synthesized in a single step from its precursor glutamate by glutamic acid decarboxylase and metabolized by successive transamination and oxidation to yield succinic semialdehyde and succinic acid, respectively. As part of the transamination reaction, a recycling system is formed in which $\alpha$-ketoglutaric acid is converted to the GABA precursor glutamate by GABA-glutamic acid transaminase. ${ }^{29}$

The cornerstone of the GABA hypothesis of bipolar disorder is that GABA provides an inhibitory action to both norepinephrine and dopamine systems. ${ }^{30}$ Although this widely expressed neurotransmitter has been thought to exert a tonic inhibitory effect on norepinephrine systems, an earlier study ${ }^{31}$ suggests that GABA may in fact facilitate norepinephrine activity. It also reported that plasma GABA levels are relatively reduced in depressed patients. The current theory of GABA and depression is that low plasma levels of GABA may identify an inheritable tendency for mood disorders such as depression or bipolar disease. ${ }^{32}$ Hence, the role of GABA in mood disorders and its interactions with serotonin and norepinephrine systems is worthy of further study. The present study investigated the alterations of GABA content in the nucleus accumbens of chronic restrained mice exposed to a chemoconvulsive substance (PTX) and treated by sodium valproate and/or paroxetine.

Additionally, the models of chemoconvulsion and chronic restraint used in this study evaluate the effect of paroxetine used alone or in combination with a widely used antiepileptic drug sodium valproate on seizure threshold and also on an oxidative stress marker, namely TBARS. The results indicate that sodium valproate alone significantly attenuated PTX-induced convulsions, decreased TBARS levels, and increased GABA contents in nucleus accumbens of tested mice. This may be attributed to an inhibitory effect of sodium valproate on dopamine-induced hyperactivity in nucleus accumbens. This inhibitory effect is similar to that by GABA to control dopaminergic function in this area of the brain. Additionally, this antiepileptic drug has been shown to inhibit the activity of succinic semialdehyde dehydrogenase and GABA transaminase enzymes involved in GABA metabolism. This action will result in an elevation of GABA content. PTX, the GABA antagonist, when injected prior to valproate blocked the reduction in locomotor activity caused by valproate. This further supports the hypothesis that the effects of valproate are mediated by the stimulation of GABA receptors. ${ }^{33}$

The oxidative stress and modulation of antioxidant enzyme activity may contribute to the central deleterious consequences of chronic stress. ${ }^{34,35}$ One of the neurochemical complications associated with epilepsy is increased lipid peroxide levels, especially TBARS, in the brain. ${ }^{36}$ Enhanced lipid peroxidation can induce seizure activity by direct activation of glutamine synthase, thereby permitting an abnormal buildup of the excitatory neurotransmitter glutamic acid. ${ }^{37}$

A single-blind, placebo-controlled, crossover trial ${ }^{38}$ demonstrated a beneficial combination of paroxetine and other antiepileptic drugs. The authors investigated possible interactions between paroxetine, a serotonin reuptake inhibitor, and carbamazepine, valproate, and phenytoin. It was carried out in 20 outpatients with epilepsy. Patients on long-term treatment with carbamazepine, valproate, or phenytoin were given a 7-day placebo treatment, followed by paroxetine cotreatment for 16 days. Side effects were infrequent and mild. None of the patients experienced epileptic seizures during this clinical study. These results support findings of paroxetine in this experimental research. Its beneficial effect, when combined with valproate, could be related to a significant reduction in TBARS and a significant increase in GABA contents in crucial brain areas such as nucleus accumbens.

Preliminary findings of clinical studies, demonstrated in a report of the American Neuropsychiatric Association Committee on Research, denoted some neuroprotective effects of drugs, eg, paroxetine and valproic acid, in neurodegenerative diseases. A recommendation was reported by these studies to perform further clinical drug trials on the use of these well-known medications, not only for their psychotropic effects but also for neuroprotection in neurodegenerative diseases. ${ }^{39}$ 


\section{Conclusion}

In conclusion, the management of epilepsy is a difficult task when associated with other neuropsychiatric disorders. Therefore, extreme caution should be exercised with respect to selection of the proper antidepressants to treat epilepsydepression comorbidities. The SSRI paroxetine could be recommended in the management of such cases, in combination with sodium valproate, as it may reduce seizure frequency and intensity most likely as a result of decreased brain levels of the oxidative stress marker TBARS with an increase in GABA content of nucleus accumbens of mice exposed to a chemoconvulsive model.

\section{Acknowledgment}

This research was supported by the Medical Research Service of the Ain Shams University, Cairo, Egypt. It was supported by the HPLC Laboratory of the Pharmacology Department, Faculty of Medicine, Ain Shams University, Cairo, Egypt.

\section{Disclosure}

The author reports no conflicts of interest in this work.

\section{References}

1. Turkdogan D, Toplan S, Karakoc Y. Lipid peroxidation and antioxidative enzyme activities in childhood epilepsy. J Child Neurol. 2002;17(9):673-676.

2. Hamed SA, Abdellah MM. Trace elements and electrolytes homeostasis and their relation to antioxidant enzyme activity in brain hyperexcitability of epileptic patients. J Pharmacol Sci. 2004;96(4): 349-359.

3. Hermann BP, Seidenberg M, Bell B, Woodard A, Rutecki P, Sheth R. Comorbid psychiatric symptoms in temporal lobe epilepsy: association with chronicity of epilepsy and impact on quality of life. Epilepsy Behav. 2000;1(3):184-190.

4. Harden CL. The co-morbidity of depression and epilepsy. Epidemiology, etiology, and treatment. Neurology. 2002;59:S48-S55.

5. Ahern TH, Javors MA, Eagles DA, et al. The effect of chronic norepinephrine transporter inactivation on seizure susceptibility in mice. Neuropsychopharmacol. 2005;27(2):13-19.

6. Blier P, De Montigny C. Current advances and trends in the treatment of depression. Trends Pharmacol Sci. 1994;15:220-226.

7. Artigas F. Selective serotonin/noradrenaline reuptake inhibitors (SNRIs). CNS Drugs. 199;4:79-89.

8. Vetulani J, Nalepa I. Antidepressants: past, present and future. Eur J Pharmacol. 2000;405:351-363.

9. Delgado PL, Price LH, Heninger GR, Charney DS. Neurochemistry of Affective Disorders. Handbook of Affective Disorders. Paytkel ES, editor. Livingston, NY: Churchill; 1992:219-253.

10. Deakin B, Dursun S. Optimizing antidepressant treatment: efficacy and tolerability. Int Clin Psychopharmacol. 2002;17(Suppl 1):S13-S24.

11. Dikeos DG, Papadimitriou GN. Genetic investigation of dopamine and GABA in mood disorders. Ann Gen Hosp Psychiatry. 2003;2:S83.

12. Prueter $C$, Norra C. Mood disorders and their treatment in patients with epilepsy. J Neuropsychiatry Clin Neurosci. 2005;17(1):20-28.

13. Buckley NA, McManus PR. Fatal toxicity of serotoninergic and other antidepressant drugs: analysis of United Kingdom mortality data. Br Med J. 2002;325:1332-1333.
14. Montgomery SA, Loft H, Sanchez C. Escitalopram (S-enantiomer of citalopram): clinical efficacy and onset of action predicted from a rat model. Pharmacol Toxicol. 2001;88(5):282-286.

15. Siddiqui A, Nazmi A, Karim S, Khan R, Pillai K, Pal K. Effect of Melatonin and Valproate In Epilepsy and Depression. Ind J Pharmacol. 2001;33:378-381

16. David D, Bourin M, Jego G, Przybylski C, Jolliet P, Gardier A. Effects of acute treatment with paroxetine, citalopram and venlafaxine in vivo on noradrenaline and serotonin outflow: a microdialysis study in Swiss mice. Br J Pharmacol. 2003;140(6):1128-1136.

17. Benjamin J, Iwata R, Hazalett J. Kinetics of entry of proteins into the myelin membrane. J Neurochem. 1978;31:1077-1085.

18. Gutteridge JM, Quinlan GJ. Malondialdhyde formation from lipid peroxides in the thiobarbituric acid test: the role of lipid radicals, iron salt and metal chelators. J Appl Biochem. 1983;5(4-5):293-299.

19. Gunawan S, Walton N, Treiman D. High performance liquid chromatography determination of selected amino acids in rat brain by precolumn derivatization with phenylisothiocyanate. J Chroma. 1990;503(1):177-187.

20. Montgomery SA. Antidepressants and seizures: emphasis on newer agents and clinical implications. Int J Clin Pract. 2005;59(12): $1435-1440$

21. Rossetti V, Lombard A. Determination of glutamate decarboxylase by high-performance liquid chromatography. J Chromatogr $B$. 1996;681:63-67.

22. Bradford MM. A rapid and sensitive method for the quantitation of microgram quantities of protein utilizing the principle of protein-dye binding. Anal Biochem. 1976;72:248-254.

23. Dailey JW, Naritoku DK. Antidepressants and seizure: clinical anecdotes overshadow neuroscience. Biochem Pharmacol. 1996;52: 1323-1329.

24. Trimble M. Non-monoamine oxidase inhibitor antidepressants and epilepsy: a review. Epilepsia. 1978;19:241-250.

25. Edwards JG. Antidepressants and convulsions. Lancet. 1979;2: 1368-1369.

26. Skowron DM, Stimel GL. Antidepressants and the risk of seizures. Pharmacotherapy. 1992;12:18-22.

27. Rosenstein DL, Nelson JC, Jacobs SC. Seizures associated with antidepressants: a review. J Clin Psychiatry. 1993;54:289-299.

28. Kanner AM. The behavioral aspects of epilepsy: an overview of controversial issues. Epilepsy Behav. 2001;1:101-105.

29. Brambilla P, Perez J, Barale F, Schettini G, Soares JC. GABAergic dysfunction in mood disorders. Mol Psychiatry. 2003;8(8): 721-737.

30. Shinsuke W, Akifumi I, Nobumasa K, Tadafumi K. Possible relationship between mitochondrial DNA polymorphisms and lithium response in bipolar disorder. The International Journal of Neuropsychopharmacology, 2003;6:421-424 doi:10.1017/S1461145703003778

31. Petty F, Kramer GL, Fulton M, Moeller FG, Rush AJ. Low plasma GABA is a trait-like marker for bipolar illness. Neuropsychopharmacology. 1993;9(2):125-132.

32. Sanacora G, Mason GF, Rothman DL, Krystal JH. Increased occipital cortex GABA concentrations in depressed patients after therapy with selective serotonin reuptake inhibitors. Am J Psychiatry. 2002;159(4): 663-665.

33. Kuruvilla A, Uretsky N. Effect of sodium valproate on motor function regulated by the activation of GABA receptors. Psychopharmacol. 1981;72:167-172.

34. Sunanda BS, Shankaranarayana R, Raju TR. Chronic restraint stress impairs acquisition and retention of spatial memory task. Current Science. 2000;79(11):1581-1584.

35. Grillo CA, Piroli GG, Rosell DR, Hoskin EK, Mcewen BS, Reagan LP. Region specific increases in oxidative stress and superoxide dismutase in the hippocampus of diabetic rats subjected to stress. Neuroscience. 2003;121(1):133-140.

36. Sudha K, Rao AV, Rao A. Oxidative stress and antioxidants in epilepsy. Clinica Chimiva Acta. 2001;303:19-24. 
37. Scharfman HE, Sollas AL, Berger RE, Goodman JH. Electrophysiological evidence of monosynaptic excitatory transmission between granule cells after seizure-induced mossy fiber sprouting. J Neurophysiol. 2003;90:2536-2547.

38. Andersen BB, Mikkelsen M, Vesterager A, Dam M, Kristensen HB, Pedersen B, et al. No influence of the antidepressant paroxetine on carbamazepine, valproate and phenytoin. Epilepsy Res. 1991;10(2-3): 201-204.
39. Lauterbach E, Mendez M. Psychopharmacological neuroprotection in neurodegenerative diseases, part III: criteria-based assessment: A report of the ANPA Committee on Research. J Neuropsychiatry Clin Neurosci. 2001;23(3):242-260.

International Journal of Nanomedicine

\section{Publish your work in this journal}

The International Journal of Nanomedicine is an international, peerreviewed journal focusing on the application of nanotechnology in diagnostics, therapeutics, and drug delivery systems throughou the biomedical field. This journal is indexed on PubMed Central, MedLine, CAS, SciSearch $\AA$, Current Contents ${ } /$ Clinical Medicine,
Journal Citation Reports/Science Edition, EMBase, Scopus and the Elsevier Bibliographic databases. The manuscript management system is completely online and includes a very quick and fair peer-review system, which is all easy to use. Visit http://www.dovepress.com/ testimonials.php to read real quotes from published authors.

Submit your manuscript here: http://www.dovepress.com/international-journal-of-nanomedicine-journal 